\title{
ROWELL'S SYNDROME IN PATIENT WITH SYSTEMIC LUPUS ERYTHEMATOSUS: CASE REPORT
}

Laís Zanlorenzi ${ }^{1, \star}$, Thelma Larocca Skare ${ }^{1}$, Victoria Smaniotto ${ }^{1}$, Gabriela Esmanioto ${ }^{1}$

1.Hospital Universitário Evangélico Mackenzie, Curitiba (PR), Brazil.

*Corresponding author: laisznl@gmail.com

\section{BACKGROUND}

Rowell's syndrome is a rare presentation of lupus erythematosus with erythema multiforme-like lesions, suggested to be a different variant of cutaneous lupus erythematosus. This syndrome is associated with positivity of antinuclear, anti-La, anti-Ro and rheumatoid factor.

\section{CASE REPORT}

We present the case of a 27-year-old female patient with systemic lupus erythematosus for 6 years, with positive anti-DNA, antiRNP and anti-La antibodies. It presented cutaneous and joint activity during the use of hydroxychloroquine and azathioprine, with lesions characteristic of Rowell's syndrome. Associated with this condition, she presented chondritis in the ear bilaterally. Showed good response to corticosteroid therapy and change of therapy to mycophenolate mofetil.

\section{CONCLUSION}

We must include Rowell's syndrome in the differential diagnosis of cutaneous lesions of lupus in order to better manage patients.

\section{KEYWORDS}

Systemic lupus erythematosus, Rowell's syndrome, Erythema multiforme-like. 